\title{
AVALIAÇÃO DE TREINAMENTO E DESENVOLVIMENTO (T\&D): UMA FUNÇÃO EM BUSCA DE RESPOSTAS
}

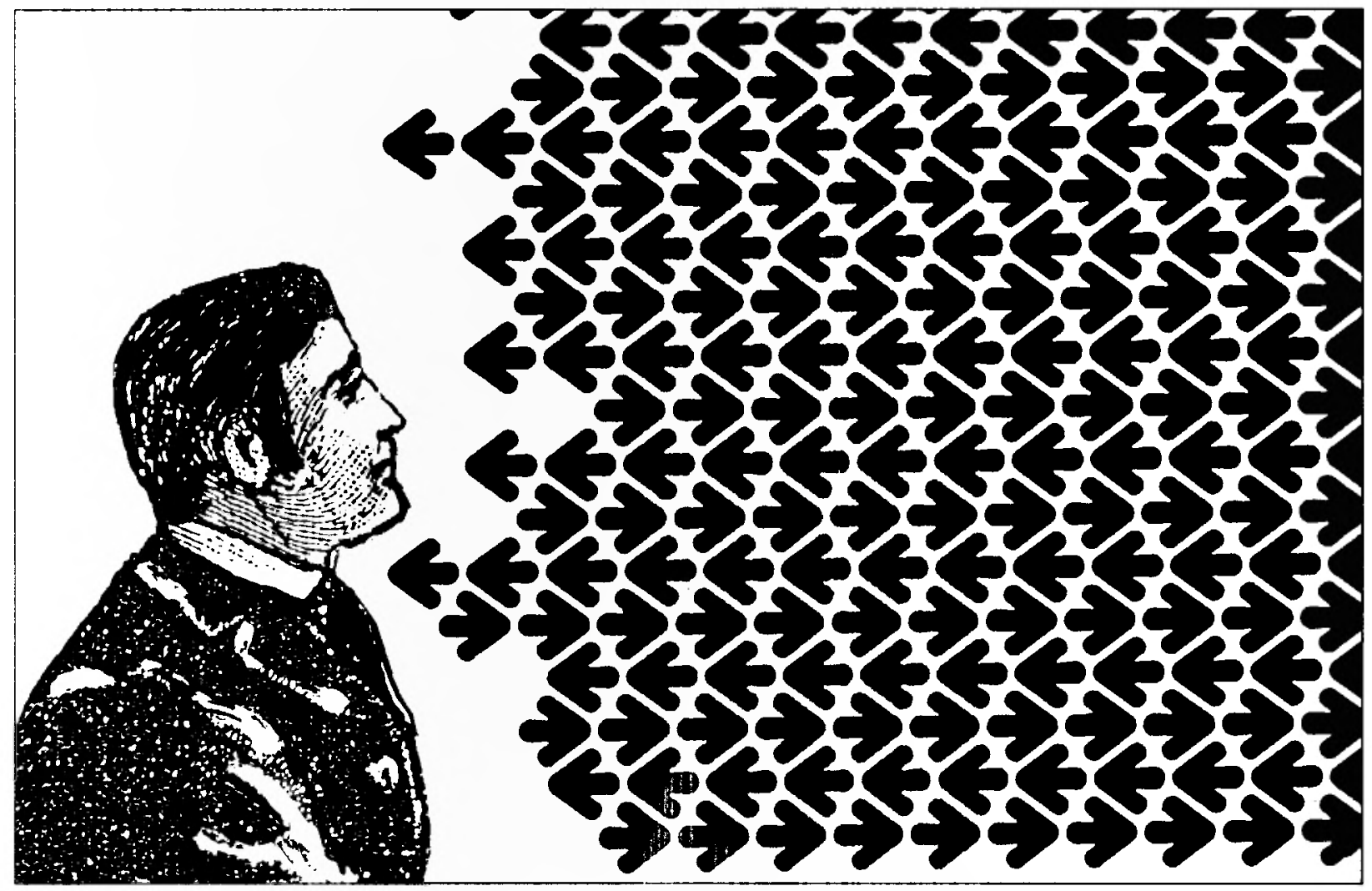

BIANOR SCELZA CAVALCANTI

Professor do Curso de Mestrado e Diretor da EBAP/FGV.

RESUMO: Este texto reflete sobre indagações centrais formuladas pelos especialistas de TED, indicando respostas derivadas de uma abordagem organizacional do problema. Trata a questão da eficácia do treinamento e desenvolvimento discutindo alguns pontos importantes quanto à natureza da atividade e sua avaliação. Traça uma revisão das posiçōes básicas da moderna teoria das organizações em sua versão sistêmico-contingencial. Revela um momento de questionamento em que os quadros teórico-conceituais ganham importância como base de reflexão para orientar uma prática conseqüente com o aperfeiçoamento do desempenho da função de $T E \mathcal{}$ ED.
PALAVRAS-CHAVE: Treinamento e desenvolvimento: avaliação; Treinamento e desenvolvimento: eficácia; Treinamento e desenvolvimento: teoria e prática.

\section{APRESENTAÇÃO}

( presente trabalho foi escrito tendo em vista subsidiar discussões e estudos referentes ao tema "Avaliação de $T \& D$ ".

Seu objetivo maior, de certa forma ambicioso, é levar os profissionais de $T \& D$ a refletirem, sistematicamente, sobre indagações centrais que os preocupam e desafiam, indicando, porém, possíveis caminhos para que respondam a tais questões.

Em sua elaboração, foram adotados alguns pressupostos básicos que convém esclarecer ao leitor. 
Em primeiro lugar, esta contribuição privilegia, radicalmente, uma abordagem organizacional do problema. Tenho forte convicção de que tal enfoque é mais oportuno, quando comparado a outros. Assim seria em relação por exemplo, a um enfoque estritamente econômico, que se limitasse a encontrar respostas técnicas à questão custo/benefícios ou um enfoque técnico-educacional, que restringisse o âmbito da abordagem a uma espécie de mergulho introspectivo da função de T\&D, em si e para si.

Em segundo lugar, assumindo meu papel de acadêmico-consultor, entendo que, a despeito de um certo preconceito dos práticos da administração em relação a teorias, é exatamente em momentos de questionamento, como este, que os quadros teórico-conceituais ganham importância como base de reflexão e orientação para uma prática conseqüente, a despeito mesmo de suas limitações.

Finalmente, parti do princípio de que seria proveitoso, para induzir reflexões e discussões, adiantar algumas orientações práticas, inferidas da reflexão teórico-conceitual e de minhas experiências junto a empresas, não obstante o fato de que tais propostas não estejam, ainda, suficientemente discutidas e amadurecidas. Esta é, efetivamente, a oportunidade que se apresenta.

O trabalho está dividido em quatro itens, cujo conteúdo passo a expor.

O item I, a seguir, contém breves reflexões sobre os porquês da avaliação.

No item II, é tratada a questão da eficácia, discutindo-se alguns pontos importantes referentes à natureza das atividades de T\&D e de sua avaliação.

$O$ item III é dedicado a uma revisão das proposições básicas da moderna Teoria das Organizações, em suas versões sistêmica, sócio-técnica e contingencial. $O$ argumento básico, que motiva essa parte, é a convicção de que tais desenvolvimentos teóricos são relevantes para o diagnóstico da função de $T \& D$ em si mesma, em diferentes contextos organizacionais, e para indicar os caminhos das possíveis respostas práticas a muitas das questões que os especialistas de T\&D hoje se colocam. Um modelo interativo das dimensões organizacionais e suas respectivas variáveis é fundamental ao desenvolvimento dessa parte.

No item IV, busca-se responder às questões práticas, específicas, colocadas pelos especialistas de $T \& D^{1}$, com base na reflexão teórico-conceitual desenvolvida no item anterior.

Limitações de tempo e espaço impediram-me de explorar mais intensamente muitos dos esquemas conceituais e idéias aqui apresentados.

Terei alcançado meu objetivo se conseguir evi- tar divagações teóricas desarticuladas e se tiver sido suficientemente provocativo para estimular uma reflexão sistemática sobre os problemas de avaliação de $T \& D$,esboçando possíveis caminhos para o encontro de soluções práticas, a partir de uma ótica organizacional mais ampla.

\section{OS PORQUÊS DA AVALIAÇÃO DE TREINAMENTO E DESENVOLVIMENTO}

A avaliação do desempenho de pessoas, subsistemas funcionais e organizações constitui um dos maiores desafios políticos de nossos tempos. Não obstante as dificuldades inerentes à avaliação de resultados, torna-se impossível fugir ao problema, por ser ele vital a questões centrais de racionalidade administrativa e justiça econômicosocial, cuja solução é básica para a sobrevivência de qualquer sistema. A menos que estabeleça uma relação apropriada entre contribuintes e retribuições, um sistema produtivo tem seu futuro ameaçado, sobretudo em ambiências caracterizadas pela escassez de recursos, dada a inexistência de um esquema referencial adequado à administração de conflitos.

No contexto sócio-econômico, no que diz respeito à empresa, a questão consiste em identificar e avaliar as contribuições do trabalho de cada trabalhador em particular e do capital de risco, para recompensá-las e desenvolvê-las. Em relação aos diferentes subsistemas funcionais, dentre eles o de Treinamento e Desenvolvimento dos Recursos Humanos, é igualmente importante avaliar sua contribuição efetiva para os resultados empresariais, para que se possam determinar adequadamente seus pesos, específico e relativo, no contexto da economia política da empresa, daí resultando as decisões de alocação de recursos, determinadoras das possibilidades e limites de sua contribuição atual e futura. No plano econômico maior, cabe a avaliação da própria empresa, estabelecida pelos mecanismos do mercado, no caso da empresa privada produtiva, e pela conjugação desses mecanismos com outros, de caráter político, no universo das empresas governamentais. Novamente, aqui, existe relação entre a avaliação dos resultados e o fluxo de insumos que retroalimenta a empresa, de forma a expandir ou restringir possibilidades e limitações de sua contribuição atual e futura.

Torna-se necessário entender, no entanto, que

1. SENAI-DN. Proposta de Estudo sobre Avaliação de Resultados de Treinamento e Desenvolvimento. Anteprojeto (mimeo), 1988. 
esses diferentes sistemas de avaliação são tão interdependentes quanto as dimensões a que se referem, sem o que se incorre em simplificações e/ou extrema severidade nos julgamentos avaliatórios. Faz-se necessário, também, compreender que a atividade de avaliação requer profundo conhecimento de sua natureza e dificuldades, para que seja possível a concepção de mecanismos de avaliação de treinamento e desenvolvimento mais racionais e justos, tendo em vista a aferição das contribuições, a conseqüente designação de recursos para essa área funcional e a própria reconcepção contínua das atividades de T\&D.

\section{EFICÁCIA DO TREINAMENTO E DESENVOLVIMENTO: NATUREZA DA AVALIAÇÃO}

Qual é o resultado desejável para as ações de T\&D? Como medir o resultado? Como saber o que produz ou causa o resultado desejável?

é natural que confrontados com essas três questões, os especialistas de T\&D se vejam envolvidos em dúvidas, perplexidades e incertezas.

"Qual é o resultado desejável para as ações de T\&D?"

Trata-se de uma questão de natureza normativa, subjetiva, que envolve, idealmente, a definição de políticas organizacionais que estabeleçam, com clareza, preferências em relação ao atendimento de múltiplos valores, os quais usualmente, contêm algum grau de conflito entre si. Como veremos mais adiante, o fato de que objetivos organizacionais e políticos não estejam claramente definidos, em muitas circunstâncias, representa grave desafio para os responsáveis pela função de T\&D na empresa.

Ao colocar o especialista diante do problema da mensuração de resultados, a segunda pergunta também apresenta desafios consideráveis.

Em última análise, a função de T\&D é induzir comportamentos considerados funcionais.

Nesse sentido, a aferição de resultdo (outcomes) requer que se comprove a efetiva adoção de comportamento e uso de habilidades e conhecimentos. De outra forma, a avaliação se restringiria ao controle dos out-puts, isto é, conhecimentos, habilidades e valores adquiridos, porém não necessariamente postos em prática. Tal avaliação é, evidentemente, de pouca valia para a aferição da relação custo-benefício do treinamento.

Ocorre, porém, que a adoção de padrões de comportamentos e o uso efetivo de habilidade e conhecimentos adquiridos é resultante, sob o ponto de vista organizacional, da ação estruturante de um conjunto complexo de dispositivos formais, dentre os quais $T \& D$ é apenas um. $O$ desafio se constitui em avaliar resultados de $T \& D$, considerando que os padrões de comportamento efetivamente adotados são influenciados, também, por "sinalizações" emitidas, não raro contraditoriamente, pela estrutura da empresa, seu sistema de recompensas, normas, estilos de chefia e direção etc.

Nesse sentido, faz-se necessária a reformulação da questão "como medir o resultado desejável?" para que se ponha esse problema fundamental em evidência, como na questão a seguir: "Como identificar a parcela exata de contribuição de T\&D na configuração de padrões de comportamentos, em face das contribuições dos demais elementos estruturantes, de forma a contabilizar êxitos e fracassos na indução de comportamentos julgados funcionais?".

A terceira questão, "como podemos saber o que produz ou causa o resultado desejável?", encontra respostas de caráter factual, inspiradas, por exemplo, nas Teorias de Aprendizagem e das Organizaçōes, além de todo o conhecimento adquirido em relação às técnicas instrucionais.

Considerando-se a indisponibilidade, comumente observada, de metas e prioridades claramente estabelecidas pela empresa, e as conseqüentes limitações que isso impõe à avaliação, como planejar T\&D e conceber adequadamente suas ações? Como enfrentar o desafio da avaliação da função de $T \& D$, sem aceitar, no entanto, um discurso injusto que reflita visão simplista da questão "investimento vs retorno"?.

Acredito que a Teoria das Organizações pode contribuir para a resposta a estas e outras perguntas que angustiam os profissionais de T\&D.

\section{UMA REVISÃO DAS \\ PROPOSIÇÕES BÁSICAS DA MODERNA TEORIA DAS ORGANIZAÇÕES}

A preocupação fundamental da Teoria Administrativa é a obtenção de eficácia e eficiência organizacionais.

No transcurso do tempo, diversas correntes do pensamento administrativo-organizacional privilegiaram o papel de diferentes variáveis e enfoques organizacionais na explicação e predição da eficiência e eficácia das organizações.

Jay Galbraith ${ }^{2}$, discípulo de James Thompson ${ }^{3}$, um dos maiores teóricos modernos do funcionalis-

2. GALBRAITH, Jay. Organization Design. Reading, Mass., Addison-Wesley, 1977.

3. THOMPSON, James. Dinâmica Organizacional. Rio de Janeiro, McGraw-Hill do Brasil, 1976. 
mo na Teoria Organizacional, proporciona um riáveis, tendo em vista esforços práticos de modemodelo integrativo daquelas diferentes valagem organizacional, como ilustra a Figura I.

\section{FIGURA 1 - DIMENSÕES ORGANIZACIONAIS}

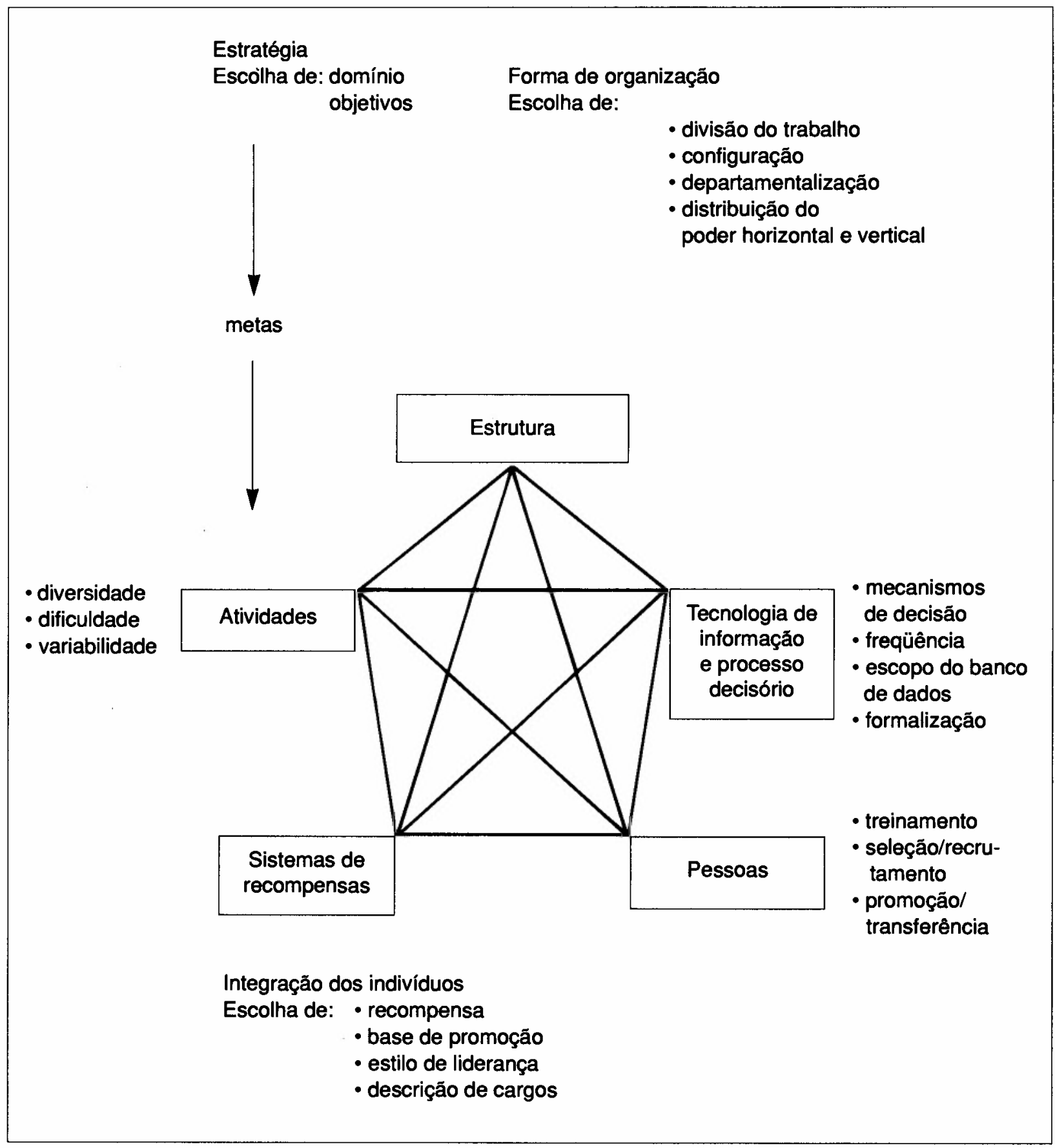

Fonte: Adaptado de GALBRAITH, Jay. Op. cit., pp. 30-31. 
O modelo contém as preocupações dos clássicos com as variáveis de "estrutura", para eles determinantes da eficácia e eficiência organizacionais: divisão do trabalho, configuração estrutural departamentalização, distribuição do poder e autoridade.

O modelo incorpora, ainda, as contribuições dos humanistas tradicionais (Relações Humanas) e modernos (DO) relativas às questões da satisfação e motivação, tais como refletidas nas dimensões organizacionais referentes a "pessoas" e "sistemas de recompensa", ilustradas pelas variáveis treinamento, recrutamento/seleção, promoção/transferência, recompensas, estilos de liderança, descrição e redesenho de cargos (enriquecimento), como também o próprio tratamento contingencial das variáveis em geral, inclusive as clássicas.

Estão presentes, também, no modelo, as preocupações de Simon e do new management com os processos decisórios e informacionais, em contraponto com a mera eficiência no executar, ditada pelos clássicos. Resumidos na idéia de "Tecnologia de Informações e Processo Decisório", estão presentes os mecanismos de decisão, a freqüência das decisões, os bancos de dados, a formalização no tratamento das informações.

O elemento de integração do modelo é o enfoque sistêmico-contingencial, que amarra o comportamento das variáveis organizacionais citadas à natureza da tarefa (atividade) da organização, determinada por seu domínio e objetivos.

Os dirigentes tomam decisões (fazem escolhas) em relação às variáveis componentes de cada dimensão citada, modelando, assim, a organização. Os resultados desse contínuo esforço de modelagem podem ser organizações eficientes e eficazes ou sistemas fadados ao insucesso.

O modelo é, por um lado, sistêmico-sócio-técnico, pois integra tecnologia (tarefa), estruturas e comportamentos (pessoas) e sistêmico-contingencial, pela amarração normativa à natureza da atividade, que estabelece como condição de eficiência e eficácia.

São três, assim, as proposições fundamentais do modelo:

1. as principais variáveis organizacionais são intimamente interdependentes;

2. para que se possa obter eficiência e eficácia organizacionais, é indispensável a obtenção de coerência e compatibilidade na modelagem das diversas variáveis organizacionais;

3. as escolhas (decisões) dos dirigentes, na formatação das variáveis organizacionais referentes às dimensões "Estrutura", "Informação e Processo Decisório", "Pessoas" e "Sistemas de Recompensas",devem atender a critérios de adequação das mesmas -- em seu conjunto e compatibilizadas entre si - à "tarefa" (atividade) da organização.

Dessa forma, um dado formato organizacional, como, por exemplo,uma estrutura do tipo matricial, é concebido para atender as necessidades impostas por um tipo de tarefa com características especiais, sendo contraproducente seu emprego como elemento estruturante de processos de decisão e execução pertinentes a outros tipos de tarefa. Por outro lado, torna-se necessário promover todo tipo de adequação entre os elementos organizacionais. O funcionamento de uma estrutura matricial requer que se desenvolvam valores e comportamentos adequados a seu funcionamento (T\&D), sistemas de recompensa coerentes com aquela estrutura e assim por diante, em relação a todas as dimensões organizacionais e suas respectivas variáveis.

O caráter contingencial do modelo reflete os desdobramentos da teoria de sistemas, decorrentes de resultados de pesquisa como aquelas conduzidas por Burns e Stalker ${ }^{4}$ e Lawrence e Lorsh. Tais resultados indicaram que:

1. a garantia de eficiência e eficácia empresariais não reside pura e simplesmente, quer na adoção de um modelo clássico burocráticomecanicista, quer de um modelo orgânico humanista-comportamental;

2. o atendimento de critérios de eficácia e eficiência está associado à adequação do modelo organizacional adotado à natureza da atividade da organização e às relações desta com o ambiente;

3. eficácia e eficiência estão associadas com o modelo mecanicista, quando a tarefa (atividade) envolve relações ambientais de certeza, estabilidade, previsibilidade. Quando as condições são de incerteza, instabilidade e imprevisibilidade, a eficácia e a eficiência organizacionais estão associadas à adoção de modelos predominantemente orgânicos;

4. dificilmente encontram-se situações passíveis de aplicação dos modelos em suas formas mais puras. Pode-se falar de organizações que, como um todo, devem aproximar-se mais

4. BURNS, T. \& STALKER, G.M. The Management of Innovation. Londres, Tavistock, 1961.

5. LAWRENCE, P. R. e LORSH, J.W. Organization and Environment. Boston, Harvard Business School, 1967. 
deste ou daquele modelo, tendo em vista a natureza de suas atividades e das relações ambientais que mantêm. Em função, no entanto, de suas subatividades e subsistemas, é comum a necessidade de algum grau de diferenciação numa mesma organização, isto é, para serem eficazes e eficientes, certos segmentos de uma mesma organização necessitam de modelagem mais mecanicista, enquanto outros, mais orgânica;

5. qualquer esforço de modelagem requer, ain- da, que se considerem alguns elementos adicionais "de calibragem", ou "ajustamento fino" na adoção deste ou daquele modelo.

São eles: a dimensão da organização, o estágio de seu desenvolvimento e o nivel do segmento sob atenção (estratégico- institucional, gerencial ou operacional).

O Quadro I ilustra, de forma simplificada, sem considerar os complicadores da "diferenciação" e da "calibragem", a perspectiva contingencial.

\section{QUADRO I : ADEQUAÇÃO DO MODELO ORGANIZACIONAL À SITUAÇÃO}

\begin{tabular}{|c|c|c|}
\hline $\begin{array}{r}\text { SITUAÇÃO (TAREFA E } \\
\text { RELAÇÕES AM- } \\
\text { BIENTAIS) } \\
\text { ORGANIZACIONAL }\end{array}$ & $\begin{array}{r}\text { CERTEZA, } \\
\text { ESTABILIDADE, } \\
\text { PREVISIBILIDADE }\end{array}$ & $\begin{array}{c}\text { INCERTEZA, } \\
\text { INSTABILIDADE, } \\
\text { IMPREVISIBILIDADE }\end{array}$ \\
\hline MECANICISTA & ADEQUAÇÃO & RIGIDEZ \\
\hline ORGÂNICO & LAISSEZ-FAIRE & ADEQUAÇĀO \\
\hline
\end{tabular}

O alcance da eficácia e da eficiência empresarial, sob o ponto de vista organizacional, portanto, depende:

1) de uma leitura (diagnóstico) da situação (natureza da atividade e relações ambientais);

2) de uma leitura (diagnóstico) do modelo organizacional adotado, em suas diferentes dimensões (estrutura, informação e decisão, sistemas de recompensas, pessoas) e respectivas variáveis (critérios de departamentalização, formalização de processos decisórios, estratégias de treinamento, mecanismo de coordenação etc.), detectando sua predominância de concepção: mecanicista ou orgânica;

3) da confirmação ou reconcepção dos modelos organizacionais, no todo ou em parte, tendo em vista sua adequação às situações diagnosticadas.

Chave para a análise da situação é o conceito operacional de "incerteza", que pode ser entendido como a diferença entre a informação (quantidade e qualidade) necessária ao desempenho da atividade e aquela efetivamente disponível para a organização antes de seu início, como demonstra a Figura II.

\section{FIGURA II: INCERTEZA DA ATIVIDADE}

Informação necessária $\left\{\begin{array}{l|l|l|}\text { Grau de incerteza } \\ \text { Informação disponivel }\end{array}\right.$

Fonte: Adaptado de Galbraith, Jay. Op. cit., p. 38. 
Claro está que, nas atividades sujeitas a graus elevados de incerteza, é durante a execução da tarefa que se busca completar o quadro de informações necessário à sua realização, lida-se com fatos e eventos novos, e tomam-se decisões, tudo em tempo quase real. Certamente, os mecanismos burocráticos tradicionais, concebidos para as condições de estabilidade e de baixa incerteza, revelam-se inadequados diante daquelas situações.

Finalmente, para concluir este resumo, cabe identificar algumas das principais fontes de incerteza a que estão sujeitos sistemas e subsistemas organizacionais. A seguir, tais fontes são especificadas, com algum comentário adicional nos casos que não são auto-explicativos:

1. indisponibilidade, imprecisão e falta de clareza da informação;

2. incapacidade de domínio completo das relações de causa-efeito, fundamentais à realização da atividade. Em certas áreas, o domínio das relações meios-fins, alcançado pelo "estado da arte", é insuficiente, como, por exemplo, no campo do tratamento das doenças mentais;

3. falta de consenso em relação aos resultados desejados;

4. indisponibilidade, ou extensão do tempo para obtenção de feedback definitivo. Mesmo quando concluídas, algumas atividades, por sua natureza, não permitem uma avaliação definitiva e inequívoca dos resultados; e

5. impossibilidade de se conhecer a probabilidade de ocorrência de eventos relevantes.

\section{IMPLICAÇÕES DAS PROPOSIÇÕES TEÓRICAS PARA O PROBLEMA DE AVALIAÇÃO DE T\&D}

Tendo por referência esse quadro conceitual que nos coloca a moderna Teoria das Organizações, pode-se vislumbrar, senão respostas, pelo menos orientações plausíveis para uma revisão das questões referentes à avaliação de resultados de T\&D, tal como formuladas no documento Proposta de Estuto sobre Avaliação de Resultados de Treinamento e Desenvolvimento ${ }^{6}$.

Em forma de proposições seguem algumas recomendações, de ordem prática, inferidas dos desenvolvimentos teóricos descritos no item anterior, bem como considerações adicionais que parecem pertinentes.

1. Em relação ao Planejamento da Empresa vs. Planejamento de T\&D.

a) "Como planejar T\&D sem dispor de metas $\mathrm{e}$ prioridades claramente estabelecidas pela empresa?"
É possível planejar T\&D sem dispor de metas e prioridades claramente estabelecidas pela empresa, desde que se desloque o ponto de referência dos objetivos para a tarefa (natureza da atividade).

Sujeitos a graus de incerteza elevados, é natural e até mesmo necessário que os sistemas organizacionais tenham objetivos e planos genéricos e "insuficientemente esclarecedores", quando vistos por uma ótica de expectativas burocráticas e mecanicistas. A análise cuidadosa da natureza da atividade do sistema organizacional e de seus subsistemas é, no entanto, um ponto de referência válido e suficientemente rico para orientar o esforço de planejamento de T\&D.

Cabe, ainda, observar que o planejamento, como sistema e função, é uma variável de modelagem sujeita aos critérios de compatibilização discutidos anteriormente. Se a natureza da atividade é caracterizada por elevado grau de incerteza, e consequientemente metas e prioridades não podem ser claramente estabelecidas, tanto o planejamento global da organização quanto o planejamento de T\&D, especificamente, devem ser modelados com a organicidade requerida pela situação. Há que se usar, por exemplo, técnicas de planejamento que incorporem a intuição informada (ex.: Delphy) e cenários alternativos, e conceber cursos de ação flexíveis e passíveis de revisão durante a execução do plano. Nesse sentido, tão ou mais importante que o plano é a existência de mecanismos de coordenação e decisão capazes de dar conta das exceções e dos eventos não previstos, em tempo real.

b) "Como obter respostas à questão 'investimento vs. retorno' (custo/benefício) em Treinamento e Desenvolvimento, tendo em vista a inexistência de um planejamento empresarial global e a inexistência de índices que sirvam de parâmetros para o planejamento do treinamento $\mathrm{e}$ desenvolvimento?"

É possível encontrarem-se respostas, se não globais, pelo menos parciais, à questão "investimento vs retorno" (custo/benefício) em T\&D.

Novamente, aqui, não se pode, e não se deve, fazer generalizações fáceis, sob pena de se cair na armadilha dos falsos dilemas que conduzem às respostas simplificadoras do tipo tudo ou nada (Ex.: estatização ou privatização, corte draconiano de despesas e investimentos vs abertura desenfreada da burra). A questão só pode ser resolvida com a aplicação de critérios, o que requer:

1) análise intensiva da tarefa e subtarefas; 2 ) re-

6. SENAI-DN. Op. cit. 
cursos à intersubjetividade e à negociação, onde for impossível maior objetividade.

Aqueles segmentos de atividade que seguem uma lógica mais mecanicista, operacional, nos quais os resultados do treinamento são mais dependentes de conhecimentos e habilidades práticas, podem ser mais facilmente tratáveis em termos de aferição de custos/benefícios, recorrendose a critérios e índices de maior objetividade. Por outro lado, existem segmentos de tarefa caracterizados por uma organicidade maior, objetivos e metas mais indefinidos, meios alternativos de execução, exceção e eventos não previsíveis, o que requer maior uso do julgamento, da iniciativa e da criatividade. Nesses casos, conhecimentos e habilidades conceituais fazem-se mais necessários, assim como valores e comportamentos mais elaborados. Nesse terreno, o conceito de desenvolvimento ganha corpo face ao de treinamento, e a aferição da relação custo/benefício torna-se mais problemática dada a própria natureza da tarefa. A aproximação da objetividade, nesses casos, deve-se dar através da intersubjetividade, exercida entre dirigentes e técnicos da área e responsáveis por $T \& D$, na busca conjunta de critérios, padrões e índices.

Nesse ponto, é necessário ter-se em conta a própria natureza da tarefa de T\&D. Quando recorremos ao modelo apresentado na Figura I, e o aplicamos, agora, diretamente ao Subsistema T\&D, é necessário darmo-nos conta da natureza orgânica dessa tarefa face às incertezas a que está sujeita. Por outro lado, é necessário explorar ao máximo o controle avaliativo maior que se pode ter nas atividades de treinamento, em comparação com as de desenvolvimento. Tomando a área como um todo, cabe a seus dirigentes e técnicos conviver com as ambigüidades inerentes à sua organicidade maior e fazer esforços para que a "diferenciação" necessária face a outros subsistemas mais mecanicistas seja compreendida e aceita.

2. Em relação às variáveis organizacionais restritivas e impulsoras da função $T \& D$.

a) "Qual a estratégia a ser adotada para se obter mais força política na área de $T \& D^{\prime \prime}$ ?

A estratégia a ser adotada para se obter mais força política na área de $T \& D$ deve considerar a interdependência e necessidade de compatibilização entre as variáveis organizacionais, de forma a atender às exigências impostas pela natureza da atividade.

Existem quatro grandes desafios empresariais: o tecnológico, referente ao produto ou serviço prestado bem como aos processos de produção ou prestação de serviços; o financeiro, que diz respeito à disponibilidade de recursos; o comercial, de in- terface com a clientela; e o organizacional. Este último, a despeito de sua importância, é o de menor peso político nas empresas, em virtude, talvez, da diversidade dos elementos que o compóem e dos grupos especializados que the dizem respeito.

Não obstante exista, como já foi apresentada, a necessidade de coerência e compatibilidade na modelagem das variáveis organizacionais, percebe-se um verdadeiro divórcio entre os grupos técnicos associados ao tratamento de cada uma delas. Planejadores, especialistas de O\&M, analistas de Sistemas Informatizados, profissionais de $\operatorname{Re}-$ cursos Humanos (entre eles especialistas em T\&D, em Cargos e Salários (recompensas), em Recrutamento e Seleção, enfim, todas essas categorias não têm procurado desenvolver um quadro conceitual comum, que lhes permita uma ação harmônica e conseqüente na definição de uma "política organizacional". A ausência dessa política (policy) face à existência de uma política de operações, de uma política financeira, e de uma política comercial, sempre mais bem definidas, compromete a força política (politics) dos segmentos administrativos em geral, e não apenas do segmento T\&D.

A busca de uma capacidade maior de influenciar decisões estratégicas é legítima e deve ser conduzida tendo em vista a adoção do conceito de uma "política organizacional" que garanta o atingimento de uma coerência maior na modelagem das variáveis organizacionais. Nesse sentido, a estratégia a ser adotada para obter-se mais força política para a área de $T \& D$ passa, obrigatoriamente, pela aliança com as demais áreas de modelagem organizacional (planejamento, O\&M, Sistemas Cargos e Salários, Recrutamento e Seleção), no sentido de desenvolver-se uma linguagem comum, ou seja, um quadro de referência conceitual compartilhado, capaz de orientar diagnósticos e proposições pertinentes ao desenvolvimento de uma política organizacional articulada e conseqüente, à altura e a serviço das demais políticas empresariais.

b) "Como praticar a afirmação de que 'cada gerente é gerente de $\mathrm{RH}^{\prime}$ ?".

Deve-se praticar a afirmação de que "cada gerente é gerente de $\mathrm{RH}^{\prime \prime}$ compartilhando-se com ele, sistematicamente, diagnósticos da tarefa e do modelo organizacional em vigor e prescrições de modelagem corretiva.

Uma vez que o modelo organizacional (inclusive T\&D) deve estar amarrado à tarefa e compatibilizado em suas diversas dimensões e respectivas variáveis, é importante considerar que o gerente substantivo é peça fundamental no diagnóstico da tarefa, na interpretação de suas características e níveis de certeza/incerteza, bem como no diagnóstico da capacidade de o modelo organizacional exis- 
tente atender ou não às necessidades de decisão, coordenação e execução impostas pela tarefa.

Cabe, então, ao gerente, compartilhar com os especialistas a modelagem de estruturas, mecanismos de coordenação, programas de treinamento e desenvolvimento etc., compatibilizados entre si e desenlados para atender às necessidades impostas pela tarefa/atividade.

Em termos bem pragmáticos, os gerentes de linha devem ser levados a compartilhar responsabilidades na identificação do conteúdo dos programas de treinamento e desenvolvimento, para as diferentes categorias funcionais sob sua supervisão, tendo por base os esforços de diagnósticos da tarefa. Nesse sentido, o gerente é um modelador organizacional (é um gerente de $\mathrm{RH}$, de O\&M, de Sistemas etc.).

\section{Em relação à função avaliação}

a) "Avaliação de resultados de treinamento vs. avaliaçăo de desempenho funcional".

Deve-se privilegiar uma noção mais ampla da função avaliação, envolvendo os resultados da ação conjunta dos elementos organizacionais.

Avaliar é atribuir valor, no caso, aos resultados de T\&D. Essa avaliação cumpre dois objetivos básicos: (1) alimentar a remodelagem de T\&D; e (2) fornecer elementos para decisões de alocação de recursos para a área. É fundamental, no entanto, ter-se em conta a diferença entre resultados de treinamento e desempenho funcional. T\&D podem, efetivamente, influenciar a escolha de comportamentos alternativos e a eficácia dos esforços despendidos por parte do indivíduo, determinando assim, em parte, o desempenho.

Ao agir sobre as habilidades e sobre a percepção do individuo em relação ao seu próprio papel, por exemplo, 'T\&D está mediando a relação esforço-desempentho. Os comportamentos evocados, no entanto, refletem também recompensas extrínsecas e percepçóes do indivíduo em relação a suas expectativas de ecjüidade. A escolha de comportamentos $c$, por conseguinte, o desempenho funcional são também resultado da interveniência de fatores relacionados a outras variáveis de modelagem (sistema de recompensas, estrutura etc.).

Nesse sentido, convém observar que T\&D, assim como os demais elementos organizacionais estruturantes, sâo modelados para induzir comportamentos tidos como funcionais, e inibir a escolha de comportamentos considerados disfuncionais. As inconsistências de modelagem, no entanto, podem gerar, e efetivamente geram, resultados que se anulam mutuamente. H comum, por exemplo, gerentes e técnicos participarem de atividades de desenvolvimento gerencial que lhes estimulam a independência de pensamento e a criatividade. Por outro lado, o exercício da autoridade na organização dá-se de maneira castrativa e os sistemas de recompensa premiam mais a lealdade aos superiores do que a competência, chegando-se, até mesmo, a punir a competência criativa. Cabe, assim, a formulação de algumas questões-chave: Por que avaliar o desempenho do funcionário, ou de uma função específica (T\&D), quando os estímulos gerados por outras funções, igualmente determinantes do desempenho funcional, não são avaliados? Por que avaliar os resultados de T\&D e falar em custo/benefício da função, sem que se avalie ou fale das mesmas coisas em relação a estruturas organizacionais, sistemas de recompensa ou recrutamento e seleçào? Por que os sistemas de T\&D têm quase sempre, formalizada, uma unidade de avaliação e essas outras funções não a têm?

Nesse ponto, parece fazer mais sentido enfatizar a avaliação da política organizacional, como um todo, a consistência e apoio mútuo (ou não) dos elementos organizacionais na geração dos comportamentos exigidos pela tarefa, do que avaliar funções isoladamente, ou, pior ainda, algumas delas, desconsiderando outras que influenciam, igualmente, resultados de desempenho.

b) "Como avaliar para se obterem resultados significativos? (Metodologias)".

A metodologia de avaliação que parece mais promissora face à natureza mais orgânica das tarefas de certos subsistemas funcionais é qualitativa, respaldada na intersubjetividade, em boa parte dos casos.

É importante que os profissionais de T\&D assumam a natureza de sua tarefa, e com segurança, não permitam que se lhes exijam abordagens, metodologias e critérios conflitantes com a própria natureza das atividades de sua função, sujeita, ela mesma, a consideráveis graus de incerteza, emanada das diferentes fontes já mencionadas.

ABSTRACT: This paper reflects on central interrogations formulated by specialists in TED providing replies derived from an organizational approach to the problem.It deals with the question of the efficiency of training and development by discussing some important points relating to the nature of the activity and its evaluation. It outlines a revision of the basic positions of the modern theory of organizations in its systemiccontingencial version. It reveals a questioning moment in which theoretical-conceptual frameworks gain importance as a basis for reflection to guide a practice consistent with the perfectioning of the performance of TED function.

KEY TERMS: Thaining and development: evaluation; training and development: efficcacy; training and development: theory and practice. 